\title{
Clinical validation of factors associated with sedentary lifestyle in adolescents
}

\author{
Validação clínica dos fatores associados ao Estilo de vida sedentário em adolescentes
}

Nirla Gomes Guedes ${ }^{1}$, Marcos Venícios de Oliveira Lopes ${ }^{1}$, Viviane Martins da Silva ${ }^{1}$, Lara Jales Rodrigues Farias ${ }^{1}$, Leonardo Alexandrino da Silva ${ }^{1}$, Cristina Costa Bessa ${ }^{2}$

Objective: to validate clinically the factors associated with nursing diagnosis sedentary lifestyle in adolescents. Methods: a cross-sectional study, developed with 158 adolescent students. The chi-square test was used to identify the association between the presence of sedentary lifestyle and associated factors. The level of significance was set at $\mathrm{p}<0.05$. Results: the prevalence of sedentary lifestyle was $68.3 \%$. The presence of associated factors such as poor knowledge about the benefits that physical activity brings to health and/or the consequences of physical inactivity, lack of resources for the practice of physical exercise, insufficient training to exercise and intolerance to activity increased the likelihood of presence of sedentary lifestyle $(\mathrm{p}<0.05)$. Conclusion: the nursing diagnosis sedentary lifestyle was prevalent among adolescents and there are specific factors that intensify the probability of developing this diagnosis.

Descriptors: Nursing Diagnosis; Sedentary Lifestyle; Adolescent Health.

Objetivo: validar clinicamente os fatores associados ao diagnóstico de enfermagem Estilo de vida sedentário em adolescentes. Métodos: estudo transversal, desenvolvido com 158 estudantes adolescentes. Aplicou-se o teste qui-quadrado para identificar a associação entre a presença de Estilo de vida sedentário e respectivos fatores associados. 0 nível de significância adotado foi $p<0,05$. Resultados: a prevalência de Estilo de vida sedentário foi de 68,3\%. A presença dos fatores associados Conhecimento deficiente sobre os benefícios que a atividade física traz à saúde e/ou sobre as consequências do sedentarismo, Falta de recursos para a prática de exercício físico, Treinamento insuficiente para fazer exercício físico e Intolerância à atividade aumentou a probabilidade da presença de Estilo de vida sedentário $(\mathrm{p}<0,05)$. Conclusão: o diagnóstico de enfermagem Estilo de vida sedentário foi prevalente entre os adolescentes e existem fatores específicos que intensificam a probabilidade de desenvolvimento desse diagnóstico.

Descritores: Diagnóstico de Enfermagem; Estilo de Vida Sedentário; Saúde do Adolescente.

\footnotetext{
${ }^{1}$ Universidade Federal do Ceará. Fortaleza, CE, Brazil.

${ }^{2}$ Centro Universitário Estácio do Ceará. Fortaleza, CE, Brazil. 


\section{Introduction}

Sedentary behavior constitutes a habit of life present throughout the world, and is found in increasing percentages in the last decade, especially among adolescents. Childhood and adolescence are important periods in the development of healthy lifestyles, since the behaviors acquired in these phases tend to perpetuate themselves over a long period of life, with biological, familial and cultural factors involved ${ }^{(1)}$.

In 2004, NANDA International (NANDA-I) included the nursing diagnosis sedentary Lifestyle (00168) in the taxonomy, belonging to Domain 1: Health Promotion, which "refers to a habit of life characterized by a low level of physical activity." This diagnosis has three defining characteristics and five related factors $^{(2)}$.

When considering the magnitude of the sedentary lifestyle, research has been conducted with the aim of generating a better understanding of the elements that make up and determine the sedentary lifestyle, including suggestions of new components for the development of this nursing diagnosis ${ }^{(3)}$.

In a conceptual analysis of the associated factors of sedentary lifestyle, it was suggested: the maintenance of the related factor insufficient training to do physical exercise; the increase of six associated factors (Lack of social support for the practice of physical exercises, Attitudes, beliefs and health habits that make difficult the practice of physical exercises, Lack of confidence for the practice of physical exercise, Mobility impaired, Intolerance to activity and Pain report); and the reformulation of four existing related factors for this diagnosis of NANDA-I (poor knowledge about the benefits that physical activity brings to health and/or the consequences of physical inactivity, lack of motivation for physical exercise, lack of interest in exercising and lack of resources) ${ }^{(3)}$.

It is pointed out that the nursing diagnoses proposed by NANDA-I are not definitive, since researches with specific populations allow improvement and make the conceptual structures more appropriate, so as to ensure more precise practical application ${ }^{(2)}$. In view of this, in this study, we considered the related factors proposed by NANDA-I, as well as those suggested after review of the elements that make up the nursing diagnosis sedentary lifestyle ${ }^{(3)}$.

Despite efforts to understand sedentary lifestyle, research on this diagnosis is still incipient, especially with adolescents, even this habit being a reality in the population of Brazilians in this age group ${ }^{(1)}$.

The survey of associated factors makes it possible to plan promotion and incentive measures for physical activity practices, and can therefore be a vital element for the prevention of diseases and chronic non-communicable diseases ${ }^{(4)}$. It is indicated that the earlier this behavior is identified and modified, the greater the possibility of avoiding the sequela of this habit, as well established in the literature ${ }^{(5)}$.

In addition, this study has the potential to contribute to the quality of NANDA-I sedentary lifestyle evidence, as it may migrate from the current 2.1 level of evidence (concept analysis, literature review and validation of judges) to 3.3 in the which have been developed clinical studies satisfactorily elaborated with small populations ${ }^{(2)}$. Therefore, it is considered indispensable the search for robust evidence that favors the inference of these indicators in clinical practice.

In this context, questions arose: what is the prevalence of sedentary lifestyle in school adolescents? Are there other factors associated with sedentary lifestyle characteristic in the adolescent population not covered by NANDA-I? What factors increase the likelihood of occurrence of sedentary lifestyle in adolescent students?

In view of the above, it was aimed to validate clinically the factors associated with nursing diagnosis sedentary lifestyle in adolescents.

\section{Methods}

It is a cross-sectional, exploratory and descriptive study, which was developed at a State Grade School and High School in the Northeast Region of Brazil. 
Inclusion criteria were between the ages of 11 and 19 and regularly enrolled in school. The established exclusion criterion was to present any physical condition that would prevent or impede the motor movements used in the evaluation of the impaired Mobility factor. It should be noted that there were no excluded adolescents.

The population consisted of 342 adolescents $^{(6)}$ who attended high school. The sample consisted of all those who met the inclusion criteria and who accepted to participate in the study, by signing the consent term (adolescent) and free and informed consent (parent/guardian). Thus, the sample was composed of 158 adolescents, in a non-probabilistic way and for convenience.

Data collection took place from February to April 2015, through interview and physical evaluation. We used a form with variables related to the sociodemographic profile and related factors of sedentary lifestyle contained in NANDA-I ${ }^{(2)}$ and those suggested by Brazilian researchers ${ }^{(3)}$. Variables related to the defining characteristics cited in the NANDA-I taxonomy (version 2015-2017), which are necessary for the evaluation and inference of sedentary lifestyle, are also included in the instrument such as choose a daily routine without physical exercise, demonstrate lack of physical conditioning and verbalize preference for activities with little physical exercise $\mathrm{e}^{(2)}$.

During physical evaluation, the authors investigated 36 movements of the ankle, knee, hip, trunk, wrist, elbow and shoulder joints. Mechanical resistance related to movement and/or local discomfort was interpreted as a signal of maximum amplitude ${ }^{(7)}$.

The evaluation of the associated factors and defining characteristics was protocol based, containing the conceptual and operational definitions of each component. The protocol was evaluated by members of a group of studies on diagnosis, interventions and nursing outcomes regarding relevance, simplicity, clarity, precision and amplitude. After the suggested adjustments, 8-hour training was conducted, with three nursing undergraduate students, for the application of the data collection instrument, in order to resolve the biases of data collection.

Prior to the data collection process, the researchers visited classrooms with students who met the inclusion criteria, explained the study objectives, and distributed the terms of free and informed consent and assent to adolescents and parents/guardians. Once the informed consent and the consent were obtained from the students and their parents/guardians, the interview and the physical evaluation were carried out in the reserved room of the school.

After the data collection was completed, the data were compiled in the Excel for Windows ${ }^{\circledR}$ software and forwarded, via e-mail, to each diagnostician for the inference process. To identify the presence or absence of the nursing diagnosis, five members of a group of studies on diagnosis, interventions and nursing outcomes were invited, being two students of the master's degree in nursing, one of the doctorate in nursing and two with title of doctorate in nursing, with capacity for the process of reasoning and diagnostic inference. The occurrence or not of the diagnosis was determined by the agreement of at least three diagnoses.

Statistical analysis was performed in the Statistical Package for the Social Sciences, version 20.0. For descriptive analysis, the prevalence of variables and measures of central tendency were made explicit. To evaluate the association between the presence of sedentary lifestyle and the associated factors, the chi-square test was applied, considering expected frequencies greater than five. To verify the magnitude of the effect between these variables, the odds ratio and confidence intervals were calculated. The level of significance was set at 0.05 .

The study complied with the formal requirements contained in the national and international regulations regulating research involving human beings, and was approved by the Research Ethics Committee, according to opinion no. 851.473. 


\section{Results}

A total of 158 adolescents from the seventh year of grade school to the third year of high school were evaluated. The majority of adolescents were male (50.6\%) and had no physical activity at school (69.6\%). Half of the adolescents were 15 years old, had attended school for up to 10 years and had a family income of $1,200.00$ reais. The mean age and schooling were, respectively, 14.8 years $( \pm 1.869)$ and 9.67 years $( \pm 1.735)$.

The diagnosis was identified in $68.3 \%$ of the sample. Among the associated factors, the most prevalent among adolescents was lack of confidence in the practice of physical exercise (60.8\%), followed by poor knowledge about the benefits that physical activity brings to health and/or the consequences of physical inactivity (51.8\%), lack of resources for physical exercise and lack of social support for physical exercise, with $45.6 \%$ and $30.4 \%$, respectively (Table 1 ).
Regarding the association between diagnosis and associated factors, five of the eleven factors analyzed had a statistically significant association with the diagnosis $(p<0.05)$. In the presence of deficient knowledge about the benefits that physical activity brings to health and/or the consequences of physical inactivity, lack of resources for physical exercise, insufficient training for physical exercise and intolerance to activity, increased approximately, in two, six, four times and once, respectively, the probabilities of the individual presenting sedentary lifestyle. For the related factor Lack of social support for the practice of physical exercises, it was not possible to calculate the odds ratio because of decimal places with the presence of numeral zero. However, when considering the calculated prevalence ratio (1.833), there was an $83.0 \%$ increase in the prevalence of the diagnosis in the presence of this related factor (Table 2).

Table 1 - Distribution of presence or absence of associated factors

\begin{tabular}{lcc}
\hline Associated factors & Presence (\%) & Absence (\%) \\
\hline $\begin{array}{l}\text { Poor knowledge about the benefits that physical activity brings to health and/or the consequences } \\
\text { of physical inactivity }\end{array}$ & $82(51.8)$ & $76(48.2)$ \\
Lack of interest in exercising & $22(13.9)$ & $136(86.1)$ \\
Lack of motivation to practice physical exercises & $60(38.0)$ & $98(62.0)$ \\
Lack of resources for physical exercise & $72(45.6)$ & $86(54.4)$ \\
Insufficient training to exercise & $34(21.5)$ & $124(78.5)$ \\
Pain report & $34(21.5)$ & $124(78.5)$ \\
Mobility impaired & $22(13.9)$ & $136(86.1)$ \\
Activity Intolerance & $24(15.2)$ & $134(84.8)$ \\
Lack of social support for physical exercise & $48(30.4)$ & $110(69.6)$ \\
Lack of confidence to practice physical exercise & $96(60.8)$ & $62(39.2)$ \\
Attitudes, beliefs and health habits that make it difficult to practice physical exercises & $38(24.1)$ & $120(75.9)$ \\
\hline \hline
\end{tabular}


Table 2 - Distribution of the participant adolescents, according to the data and the occurrence of sedentary lifestyle and associated factors

\begin{tabular}{|c|c|c|c|c|c|c|}
\hline \multirow{2}{*}{ Variables } & \multicolumn{2}{|c|}{ Sedentary lifestyle } & \multirow{2}{*}{ Total } & \multirow{2}{*}{$\mathbf{p}^{*}$} & \multirow{2}{*}{$\mathbf{C R}^{\dagger}$} & \multirow{2}{*}{$\mathbf{C I}^{\S}$} \\
\hline & Present & Absent & & & & \\
\hline \multicolumn{7}{|c|}{ 1. Associated factors } \\
\hline \multicolumn{7}{|c|}{$\begin{array}{l}\text { 1.1. Poor knowledge about the benefits that physical activity brings to } \\
\text { health and/or the consequences of physical inactivity }\end{array}$} \\
\hline Present & 64 & 18 & 82 & & & \\
\hline Absent & 44 & 32 & 76 & 0.006 & 2.586 & $1.293-5.173$ \\
\hline Total & 108 & 50 & 158 & & & \\
\hline \multicolumn{7}{|c|}{ 1.2. Lack of interest in exercising } \\
\hline Present & 18 & 4 & 22 & & & \\
\hline Absent & 90 & 46 & 136 & 0.143 & 2.300 & $0.735-7.193$ \\
\hline Total & 108 & 50 & 158 & & & \\
\hline \multicolumn{7}{|c|}{ 1.3. Lack of motivation to practice physical exercises } \\
\hline Present & 46 & 14 & 60 & & & \\
\hline Absent & 62 & 36 & 98 & 0.079 & 1.908 & $0.923-3.942$ \\
\hline Total & 108 & 50 & 158 & & & \\
\hline \multicolumn{7}{|c|}{ 1.4. Lack of resources for physical exercise } \\
\hline Present & 63 & 9 & 72 & & & \\
\hline Absent & 45 & 41 & 86 & 0.000 & 6.378 & $2.818-14.432$ \\
\hline Total & 108 & 50 & 158 & & & \\
\hline \multicolumn{7}{|c|}{ 1.5. Insufficient training to exercise } \\
\hline Present & 30 & 4 & 34 & & & \\
\hline Absent & 78 & 46 & 124 & 0.005 & 4.423 & $1.465-13.355$ \\
\hline Total & 108 & 50 & 158 & & & \\
\hline \multicolumn{7}{|c|}{ 1.6. Pain report } \\
\hline Present & 24 & 10 & 34 & & & \\
\hline Absent & 84 & 40 & 124 & 0.752 & 1.143 & $0.499-2.616$ \\
\hline Total & 108 & 50 & 158 & & & \\
\hline \multicolumn{7}{|c|}{ 1.7. Mobility impaired } \\
\hline Present & 18 & 4 & 22 & & & \\
\hline Absent & 90 & 46 & 136 & 0.143 & 2.300 & $0.735-7.193$ \\
\hline Total & 108 & 50 & 158 & & & \\
\hline \multicolumn{7}{|c|}{ 1.8. Activity Intolerance } \\
\hline Present & 22 & 2 & 24 & & & \\
\hline Absent & 86 & 48 & 134 & 0.008 & 6.140 & $1.384-27.241$ \\
\hline Total & 108 & 50 & 158 & & & \\
\hline \multicolumn{7}{|c|}{ 1.9. Lack of social support for physical exercise } \\
\hline Present & 48 & 0 & 48 & & & \\
\hline Absent & 60 & 50 & 110 & 0.000 & $1.830^{\ddagger}$ & $1.546-2.174$ \\
\hline Total & 108 & 50 & 158 & & & \\
\hline \multicolumn{7}{|c|}{ 1.10. Lack of confidence to practice physical exercise } \\
\hline Present & 70 & 26 & 96 & & & \\
\hline Absent & 38 & 24 & 62 & 0.125 & 1.700 & $0.861-3.360$ \\
\hline Total & 108 & 50 & 158 & & & \\
\hline \multicolumn{7}{|c|}{$\begin{array}{l}\text { 1.11. Attitudes, beliefs and health habits that make it difficult to practice } \\
\text { physical exercises }\end{array}$} \\
\hline Present & 28 & 10 & 38 & & & \\
\hline Absent & 80 & 40 & 120 & 0.418 & 1.400 & $0.619-3.165$ \\
\hline Total & 108 & 50 & 158 & & & \\
\hline
\end{tabular}




\section{Discussion}

It is pointed out as limitation of this study the use of diagnostics as reference standard for diagnostic inference, despite the understanding of being an adequate strategy when there is no perfect gold standard. In addition, because it was a cross-sectional study, the measure of association used was not the most adequate, and it was possible to estimate certain associated factors.

Among the public health problems of the 21st century, physical inactivity is relevant due to the relevant association with the development of chronic non-communicable diseases ${ }^{(4)}$. The prevalence of sedentary lifestyle in this study was $68.3 \%$. In a study that analyzed the sedentary behavior of 1,009 adolescents, it was detected a prevalence of $81.6 \%$ of this behavior among the interviewees ${ }^{(8)}$. In another study involving the clinical validation of this diagnosis with 564 adolescents, with a mean age of 16.18 years $( \pm 1.13)$ and a discrete majority of females (52.1\%), the prevalence was lower: $48.6 \%{ }^{(4)}$. It is also mentioned that the results of a systematic review on sedentary behavior revealed fluidity in the prevalence of sedentarism among Brazilian adolescents, thus highlighting the cultural and regional context and the relationships with health practices and self-care ${ }^{(9)}$.

In relation to the most prevalent associated factors, the American study pointed out that the physical inactivity is related to the social environment in which the population is inserted and the socioeconomic profile, being these barriers more difficult to overcome among adolescents, because they have limited control of them ${ }^{(10)}$. The lack of resources was reported by $61.3 \%$ of the 564 schoolchildren $^{(4)}$. In contrast, moderate economic status has recently been associated with Internet addiction and other low-intensity physical activities ${ }^{(5)}$.

The study points out that factors such as the absence of urban security, long periods of time in front of television and the scarcity of public policies aimed at cultural activities during leisure time may justify the reduction of physical activity among adolescents ${ }^{(11)}$. Regarding the existence of appropriate places to practice physical activity, studies indicate that, despite public investments made to promote health, such as health academies, available in public squares, there is still no compliance by adolescents and young people $^{(12-13)}$.

Days of rain (79.1\%), lack of time (75.3\%) and appropriate place $(52.3 \%)$ were also cited in a study conducted with 510 adolescents aged 13 to 19 years. The lack of trust was noted by only $30.0 \%$ of adolescents $^{(14)}$. On the other hand, when evaluating the confidence scores of 1,698 adolescents aged 14 to 18 years, through the self-efficacy scale for physical activity, a very strong relationship was found between high levels of confidence and persistence in performing physical activities regularly ${ }^{(15)}$.

Still in the social context, the school is configured as a setting for relationships that welcomes adolescents, during which they are in a period of growth, development and knowledge construction. In this context, the School Health Program emerged as the school's public policy in Brazil. Among its objectives, it aims to bring education and health networks together, favoring the dissemination of knowledge, including in the context of empowerment for habits that positively impact the health, such as physical exercise. The program also aims to familiarize the students with the various modalities of physical practices/physical activities, possibility of increasing the periodicity and improvement of the abilities to adequately perform these exercises ${ }^{(16)}$.

When evaluating 1,609 schoolchildren from 14 to 18 years old, in the city of Curitiba, laziness (45.8\%), lack of companionship (43.5\%), inadequate weather (43.3\%) and incapacity to perform the exercises $3.91 \%$ ) were statistically associated with physical inactivity. It is also pointed out that the fact of not being able to perform physical exercise may be related to insufficient training to exercise and intolerance 
to activity ${ }^{(17)}$. A similar relationship was found in the study of sedentary lifestyle in hypertensive patients, in whom Insufficient training to exercise and Intolerance to activity, a factor proposed in a review of the diagnosis ${ }^{(3)}$, increased the probability of the presence of the diagnosis with prevalence ratios of 1.37 and 1.26 , respectively ${ }^{(18)}$. It is highlighted that the absence of sufficient training and tolerance to the activity triggers a decline in cardio respiratory capacity and the potential to develop work in muscle mass ${ }^{(3)}$.

Lack of social support for physical exercise also proved to be important for the development of sedentary lifestyle when it was observed that the prevalence of hypertensive diagnosis increased by $47.0 \%{ }^{(18)}$. This relationship was evidenced in a systematic review, which analyzed 23 articles, which pointed out that social support, represented by family members, friends and colleagues is directly and positively related to the practice of physical exercise among adolescents, and this relationship is greater when there is a risk/ presence of overweight. Family, friends and/or community support can motivate physical exercise, with the family being the main source of support, including material, emotional and cognitive support ${ }^{(19-20)}$.

In view of the findings, it is perceived that sedentarism is a global and national concern, and that the prevalence, although varying according to country and region analyzed, is quite significant. Faced with the associated factors that influence this practice, it is necessary to intervene with health professionals in order to solve this public health problem. Thus, we suggest an interdisciplinary approach of health professionals, together with the school, to promote the health of schoolchildren, in which the nurse is guaranteed the elaboration and implementation of health actions that contemplate the cognitive, affective and psychomotor aspects of adolescents, regarding the practice of physical activity. Future studies are recommended to investigate the possible relationship between sex, family income (social vulnerability) and related factors of sedentary lifestyle.

\section{Conclusion}

This study pointed to a high prevalence of sedentary lifestyle among school adolescents and four valid factors that increase the probability of developing this diagnosis, one of which does not belong to the taxonomy of NANDA-I, Intolerance to activity.

\section{Acknowledgments}

To the Coordenação de Aperfeiçoamento de Pessoal de Nível Superior for the granting of scholarships.

\section{Collaborations}

Guedes NG and Lopes MVO contributed with the design or data analysis and interpretation. Farias LJR and Silva LA collaborated with writing the article and critically reviewing the intellectual content. Silva VM and Bessa CC assisted in writing, relevant critical revision of the intellectual content and final approval of the version to be published.

\section{References}

1. Ferrari TK, Cesar CL, Alves MC, Barros MB, Goldbaum M, Fisberg RM. Healthy lifestyle in São Paulo, Brazil. Cad Saúde Pública. 2017; 33(1):1-12. doi: dx.doi.org/10.1590/0102-311X00188015

2. Herdman TH, Kamitsuru S. NANDA international nursing diagnoses: definitions and classification 2015-2017. Oxford: Wiley Blackwell; 2014.

3. Guedes NG, Lopes MVO, Cavalcante TF, Moreira RF, Araújo TL. Review of nursing diagnosis sedentary lifestyle in individuals with hypertension: conceptual analysis. Rev Esc Enferm USP. 2013; 47(3):742-9. doi: dx.doi.org/10.1590/S0080623420130000300031

4. Oliveira MR, Silva VM, Guedes NG, Lopes MVO. Clinical validation of the "sedentary lifestyle" nursing diagnosis in secondary school students. J Sch Nurs. 2015; 32(3):186-94. https://doi. org/10.1177/1059840515588956 
5. Gür K, Yurt S, Bulduk S, Atagöz S. Internet addiction and physical and psychosocial behavior problems among rural secondary school students. Nurs Health Sci. 2015; 17(3):331-8. doi: https:// doi.org/10.1111/nhs.12192

6. World Health Organization. Adolescent health and development [Internet]. 2017 [cited Jan 16, 2019]. Available from: www.searo.who.int/entity/child_ adolescent/topics/adolescent_health/en/

7. Araújo CGS. Flexitest: an innovative flexibility assessment method. Champaign: Human Kinetics; 2014.

8. Lourenço CLM,Zanetti HR, Amorim PRS, Mota JAPS, Mendes EL. Sedentary behavior in adolescents: prevalence and associated factors. R Bras Ci Mov [Internet]. 2018 [cited Apr 28, 2019]; 26(3):2332. Available from: https://portalrevistas.ucb.br/ index.php/RBCM/article/view/6929/pdf

9. Arancibia BA, Silva FC, Santos PD, Gutierres Filho PJ, Silva R. Prevalence of physical inactivity among adolescents in Brazil: systematic review of observational studies. Educ Fis Deporte. 2015; 34(2):331-58. doi: doi.org/10.17533/udea.efyd. v34n2a03

10. Beighle A, Morrow JR. Promoting physical activity: addressing barriers and moving forward. J Phys Educ Recreat Dance. 2014; 85(7):23-6. doi: doi.or $\mathrm{g} / 10.1080 / 07303084.2014 .937190$

11. Burgos MS, Gaya AC, Malfatti CRM, Muller A, Burgos LT, Pohl HH, et al. Lifestyle: leisure and recreational activities of school children from Santa Cruz do Sul. Rev Bras Educ Fis Esp. 2014; 23(1):77-86. doi: https://doi.org/10.1590/ S1807-55092009000100007

12. Sá GB, Dornelles GC, Cruz KG, Amorim RC, Andrade SS, Oliveira TP, et al. The Health Academy Program as a strategy to promote health and healthy lifestyles: the national implementation scenario. Ciênc Saúde Coletiva. 2016; 21(6):184960.doi:https://dx.doi.org/10.1590/141381232015216.09562016
13. Fernandes PA, Andrade ACS, Costa DS, Dias MAS, Malta DC, Caiaffa WT. Health Academies Program and the promotion of physical activity in the city: the experience of Belo Horizonte, Minas Gerais state, Brazil. Ciênc Saúde Coletiva. 2017; 22(12):3903-14. doi: dx.doi.org/10.1590/1413812320172212.25282017

14. Müller WA, Silva MC. Barreiras à prática de atividades físicas de adolescentes escolares da zona rural do sul do Rio Grande do Sul. Rev Bras Ativ Fis Saúde. 2014; 18(3):344-53. doi: https:// doi.org/10.12820/rbafs.v.18n3p344

15. Souza CA, Rech CR, Sarabia TT, Añez CRR, Reis RS. Self-efficacy and physical activity in adolescents in Curitiba, Paraná State, Brazil. Cad Saúde Pública. 2014; 29(10):2039-48. doi: https://doi. org/10.1590/0102-311X00127312

16. Ministério da Saúde (BR). Secretaria de Atenção à Saúde, Departamento de Atenção Básica. Passo a passo PSE: tecendo caminhos da intersetorialidade [Internet]. 2014 [citado 2019 jan. 30]. Disponível em: http://189.28.128.100/dab/docs/ legislacao/passo_a_passo_pse.pdf

17. Santos MS, Hino AA, Reis RS, Rodriguez-Añez CR. Prevalence of barriers for physical activity in adolescents. Rev Bras Epidemiol. 2014; 13(1):94104. doi: https://doi.org/10.1590/S1415790X2010000100009

18. Martins LCG, Lopes MVO, Guedes NG, Nunes MM, Diniz CM, Carvalho, PMO. Sedentary lifestyle in individuals with hypertension. Rev Bras Enferm. 2015; 68(6):1005-12. doi: doi.org/10.1590/00347167.2015680602i

19. Fitzgerald A, Fitzgerald N, Aherne C. Do peers matter? A review of peer and/or friends' influence on physical activity among American adolescents. J Adolesc. 2014; 35(4):941-58. doi.org/10.1016/j. adolescence.2012.01.002

20. Mendes CRS, Miranda MDC, Lima FET, Brito EAWS, Freitas I, Matias EO. Self-care practice of patients with arterial hypertension in primary health care. Rev Rene. 2016; 17(1):52-9. doi: http://dx.doi. org/10.15253/2175-6783.2016000100008 